Original Research Article

\title{
A comparative analysis of hydrochlorothiazide and chlorthalidone induced hyponatremia at the dose commonly prescribed in clinical practice
}

\author{
Sura Kishore Mishra ${ }^{1}$, Abinash Panda ${ }^{2 *}$
}

${ }^{1}$ Department of Cardiology, M.K.C.G. Medical College, Berhampur, Odisha 760004, India

${ }^{2}$ Department of Pharmacology, Government Medical College and Hospital, Balasore, Odisha 756019 India

Received: 01 March 2018 Accepted: 29 March 2018

*Correspondence to: Dr. Abinash Panda, Email: drabinashpanda@ rediffmail.com

Copyright: (C) the author(s), publisher and licensee Medip Academy. This is an openaccess article distributed under the terms of the Creative Commons Attribution NonCommercial License, which permits unrestricted noncommercial use, distribution, and reproduction in any medium, provided the original work is properly cited.

\begin{abstract}
Background: Despite the differences in cardiovascular outcomes, pharmacokinetics, pharmacodynamics, the diuretics, chlorthalidone (CTD) and hydrochlorothiazide (HCTZ) are often considered as interchangeable. There is an on-going debate whether CTD should be preferred over HCTZ, because it appears to be more effective in the prevention of cardiovascular events. The relative difference in the incidence of hypokalemia and hyponatremia, is also a topic of debate. With this background, the study was carried out to compare the prevalence of hyponatremia between CTD and HCTZ used in the treatment of hypertension at the dose commonly prescribed in clinical practice.

Methods: This was a cross sectional study carried out on a convenience sample of 74 adult patients with provisional diagnosis of hyponatremia or with a plasma sodium level of less than $135 \mathrm{mmol} / \mathrm{L}$ and having a history of anti-hypertensive use of HTCZ or CTD in the dose range of $12.5-25 \mathrm{mg} /$ day and $6.25-12.5 \mathrm{mg} /$ day respectively. Chi square test and independent samples ' $\mathrm{t}$ ' test were used analyse the results in GraphPad Prism 6.0.

Results: HCTZ was found to be the preferred diuretic in hypertension, whereas CTD was preferred in the age group of 65-74 years. The symptoms indicative of hyponatremia as well as a lower plasma sodium level were more common in the HTCZ treated group. Patients of hypertension using CTD were less predisposed to hyponatremia (OR 0.804, 95\% CI 0.207-3.12).

Conclusions: Chlorthalidone, when used at a lower dose of $6.25-12.5 \mathrm{mg} / \mathrm{day}$ for the treatment of hypertension cause a lesser risk of hyponatremia than hydrochlorothiazide.
\end{abstract}

Keywords: Anti-hypertensive, Chlorthalidone, Hydrochlorothiazide, Hyponatremia

\section{INTRODUCTION}

Thiazide and thiazide like diuretics have been used in the management of hypertension for a longer period than any other anti-hypertensive agent. ${ }^{1}$ They are recommended as the first line agents by the JNC 7 . They have also been included as a major class of anti-hypertensives in the JNC 8 recommendations. Thiazide diuretics are often considered a homogeneous therapeutic class, where all agents reduce cardiovascular event risk and all-cause mortality in elderly hypertensive patients equally, as a direct consequence of anti-hypertensive effects. ${ }^{2}$ However, not all thiazide-related medications have the same properties. Many studies have contrasted the most widely used thiazide diuretic, hydrochlorothiazide (HCTZ), and the thiazide-like diuretic, chlorthalidone (CTD), with 
respect to duration of action, anti-hypertensive potency, non-blood pressure-related pleiotropic features, reduction of left ventricular hypertrophy, and reduction of cardiovascular events. ${ }^{3}$ These studies have been accompanied by many helpful commentaries contrasting the two medications. While hydrochlorothiazide is the prototype thiazide, chlorthalidone is aphthalimidine possessing distinct pharmacokinetics. ${ }^{4}$

Thiazide diuretics act by inhibiting reabsorption of $\mathrm{Na}+$ and $\mathrm{Cl}^{-}$from the distal convoluted tubule by blocking the thiazide-sensitive $\mathrm{Na}+\mathrm{Cl}$ co-transporter. Thus, they inhibit electrolyte transport in the diluting segment and may impair urinary dilution in some vulnerable groups. Virtually, all cases of severe diuretic-induced hyponatremia have been due to a thiazide-type diuretic. ${ }^{5}$ Much attention has been paid to diuretics-induced hypokalaemia and a combination of low-dose hydrochlorothiazide with potassium sparing diuretic has been recommended to lower the risk of sudden cardiac death. ${ }^{6-8}$ Less attention has been paid to other metabolic and electrolyte alterations such as hyponatraemia, hyperglycaemia, hyperuricaemia, hypercalcaemia and hypercholesterolaemia. Further, chlorthalidone and hydrochlorothiazide are often considered as interchangeable. Although dose recommendations for initiation of therapy for hypertension with CTD or HCTZ in prescribing information and clinical guidelines are identical, it is evident from many studies that these medications are not equipotent on a milligram-tomilligram basis. ${ }^{9}$ However, greater (night time) blood pressure reduction, and alleged pleiotropic effects have renewed the interest in chlorthalidone. A recent study showed an increased risk of adverse events with chlorthalidone, including hyponatremia. ${ }^{10}$ In absence of direct head-to-head studies with clinical endpoints, a debate is on-going whether CTD should be preferred over HCTZ, because it appears to be more effective in the prevention of cardiovascular events. The relative difference in the incidence of adverse events, in particular hypokalemia and hyponatremia, is also a topic of debate. With this background, this observational study was carried out to further quantify the relative prevalence of hyponatremia, in the use of the two commonly used diuretics in treatment of hypertension at the dose commonly prescribed in clinical practice.

\section{Primary and secondary objectives}

The primary objective was to compare the prevalence of hyponatremia between CTD and HCTZ. The secondary objectives were to identify the pattern of use of different diuretics in hypertension and to characterise the clinical presentation at admission of the patients who had developed diuretic induced hyponatraemia.

\section{METHODS}

This was an analytical cross sectional study carried out in the emergency out-patient of M.K.C.G. Medical College and Hospital for a period of four months from March to June 2017.

\section{Sample size calculation, sampling technique and bias}

Assuming an estimated risk difference of $16 \%$, the desired sample size was calculated to be 74 , at a power of $80 \%$ and a two sided desired confidence level of $95 \%$, using nMasters (Developed by Department of Biostatistics, CMC, Vellore). ${ }^{10,11}$ The study participants were included using convenience sampling technique. The source population was the patients in the emergency out-patient of the tertiary care teaching hospital with the provisional diagnosis of hyponatremia. As rates of hourly visits of patients varied markedly within each day, to limit the potential for sampling bias, time slots were defined a priori covering the 24-h day. Subsequently, these predefined time slots, throughout the four months of the study period were randomly allocated using a random digit table for recruiting the study participants. During each data collection session, consecutive patients with a provisional diagnosis of hyponatremia were included in the absence of any exclusion criteria, only after obtaining their written informed consent.

\section{Participant enrolment and data collection}

All adult patients with provisional diagnosis of hyponatremia were eligible for study enrolment. For the present study a plasma sodium concentration $<135 \mathrm{mmol} / \mathrm{L}$ at admission was considered as hyponatremia. ${ }^{12}$ At the time of their coming to the emergency OPD, patients and/or their relatives were informed about the study and the relevance to participate. Written informed consent was obtained and consenting patients and/or their relatives were subsequently included in the absence of exclusion criteria. The investigators along with one assistant specifically trained for the study, collected the data.

\section{Inclusion criteria and exclusion criteria}

All the patients with provisional diagnosis of hyponatremia or with a plasma sodium level of less than $135 \mathrm{mmol} / \mathrm{L}$ and having a history of anti-hypertensive use, treatment naïve for the present illness and those willing to participate were included in the study. Patients taking HTCZ and CTD in the dose range of $12.5-25 \mathrm{mg} /$ day and $6.25-12.5 \mathrm{mg} /$ day were included to ensure a proper comparison. These were the dose commonly used in clinical practice. The selection of patients on low dose of either drug was done to control the confounding effect of dose. Patients with a prior administration of i.v fluids for the current illness, treated or medicated elsewhere for the present illness, not taking HTCZ and CTD within the selected dose range, with an history of decompensated heart failure, chronic kidney disease, diabetes ketoacidosis, acute cerebrovascular accident within the last one month, cirrhosis of liver, malignancy, pregnancy and those unwilling to participate were excluded from the study. 


\section{Study tool}

A pre-designed case record form was used to collect the demographic details, disease and medication history of the patients. The case record form had two parts. The first part collected data on the patient demographics (gender and age), the type of medication used, number of drugs requested and past history of similar illness. The second part collected the information on the symptoms attributing to hyponatremia and plasma sodium level done immediately after admission to the emergency O.P.D.

\section{Statistical analysis of data}

The collected data was analysed using GraphPad Prism 6.0 (free trial version). Descriptive statistics was used to represent the patient demographic, disease and medication history. Chi square test was used to find out the association between the use of the diuretics and hyponatremia. Independent samples ' $t$ ' test was used to compare the mean plasma sodium level in the two groups. A p value $<0.05$ was considered to be statistically significant.

The present study was approved by the Institutional Ethics Committee of M.K.C.G. Medical College, Berhampur, Odisha (Approval No. 518/2017). Written informed consent was obtained from the patient or their relatives after explaining them, the implications of the study.

\section{RESULTS}

In the present study, HCTZ was found to be the preferred diuretic in hypertension and was prescribed to a majority (55\%) of the study participants. In this age group of 65-74 years, CTD was the preferred diuretic. More number of male hypertensives were prescribed CTD (53\%), whereas HTCZ was preferred in female hypertensives (63\%). Of the patients having stage 1 hypertension $65 \%$ were prescribed HTCZ, but in patients with stage 2 hypertension $68 \%$ were using CTD. Patients with hypertension for more than one month were found using HTCZ. About $43 \%$ of the patients included in the study had at least one symptom of hyponatremia. The symptoms indicative of hyponatremia was common in the HTCZ treated group $(46.34 \%)$ than in the CTD treated group (39.3\%). The prevalence of hyponatremia, as evidenced by plasma sodium level, in the HTCZ treated group was $14.63 \%$ where as in the CTD treated group it was $12.12 \%$ (Table 1). Patients of hypertension using CTD were less predisposed to hyponatremia (OR 0.804 , 95\% CI 0.207 3.12).

A descriptive analysis of the occurrence of the symptoms that led to a provisional diagnosis of hyponatremia with the use of either diuretic revealed that altered sensorium was the commonest symptom in $52 \%$ of the study participants. This was followed by vertigo and vomiting in HTCZ and CTD groups respectively (Table 2).
Table 1: Patient characteristics and use of hydrochlorthiazide and chlorthalidone.

\begin{tabular}{|c|c|c|c|}
\hline \multirow{2}{*}{$\begin{array}{l}\text { Patient } \\
\text { characteristics }\end{array}$} & \multicolumn{2}{|c|}{ Diuretic used } & \multirow{2}{*}{$\begin{array}{l}\text { Chi } \\
\text { square, } \\
\text { p value }\end{array}$} \\
\hline & $\begin{array}{l}\text { HTCZ } \\
n=41(\%)\end{array}$ & $\begin{array}{l}\text { CTD } \\
\mathrm{n}=33(\%)\end{array}$ & \\
\hline \multicolumn{3}{|l|}{ Age in years } & \multirow{5}{*}{$\begin{array}{l}4.73 \\
0.192\end{array}$} \\
\hline $45-54$ & $5(12.19)$ & $1(3.03)$ & \\
\hline $55-64$ & $10(24.39)$ & $4(12.2)$ & \\
\hline $65-74$ & $17(41.46)$ & $20(60.6)$ & \\
\hline$>75$ & $9(21.95)$ & $8(24.2)$ & \\
\hline \multicolumn{3}{|l|}{ Gender } & \multirow{3}{*}{$\begin{array}{l}1.77 \\
0.182\end{array}$} \\
\hline Male & $16(39.02)$ & $18(54.5)$ & \\
\hline Female & $25(60.97)$ & $15(45.4)$ & \\
\hline \multicolumn{3}{|l|}{$\begin{array}{l}\text { Stage of } \\
\text { hypertension }\end{array}$} & \multirow{3}{*}{$\begin{array}{l}2.85 \\
0.91\end{array}$} \\
\hline $\begin{array}{l}\text { Stage } 1 \\
(\mathrm{BP} \geq 140 / 90 \mathrm{~mm} \\
\mathrm{Hg})\end{array}$ & $23(56.09)$ & $12(36.3)$ & \\
\hline $\begin{array}{l}\text { Stage } 2 \\
(\mathrm{BP} \geq 160 / 100 \mathrm{~m} \\
\mathrm{mHg})\end{array}$ & $18(43.9)$ & $21(63.6)$ & \\
\hline $\begin{array}{l}\text { Symptoms of } \\
\text { Hyponatrimea }\end{array}$ & $19(46.34)$ & 13(39.3) & $\begin{array}{l}2.85 \\
0.091\end{array}$ \\
\hline \multicolumn{3}{|l|}{$\begin{array}{l}\text { Plasma Na } \\
(\mathrm{mmol} / \mathrm{L})\end{array}$} & \multirow{4}{*}{$\begin{array}{l}1.56 \\
\text { (Yates } \\
\text { chi } \\
\text { square } \\
\text { value), } \\
0.457\end{array}$} \\
\hline $120-134$ & $2(4.87)$ & $4(12.1)$ & \\
\hline $110-119$ & $3(7.31)$ & $0(0)$ & \\
\hline$<110$ & $1(2.43)$ & $0(0)$ & \\
\hline \multicolumn{3}{|l|}{$\begin{array}{l}\text { Duration of } \\
\text { diuretic use }\end{array}$} & \multirow{3}{*}{$\begin{array}{l}8.38 \\
0.003\end{array}$} \\
\hline$<1$ month & $9(21.95)$ & $18(54.5))$ & \\
\hline$>1$ month & $32(78.04)$ & $15(45.4)$ & \\
\hline
\end{tabular}

Table 2: Symptoms of hyponatrimea with use of hydrochlorthiazide and chlorthalidone.

\begin{tabular}{|lll|}
\hline Symptom & $\begin{array}{l}\text { HTCZ } \\
\mathbf{n = 4 1}(\%)\end{array}$ & $\begin{array}{l}\text { CTD } \\
\mathbf{n}=33(\%)\end{array}$ \\
\hline Anorexia & $4(9.75)$ & $1(3.03)$ \\
\hline Vomiting & $20(48.78)$ & $11(33.3)$ \\
\hline Seizures & $2(4.87)$ & $1(3.03)$ \\
\hline Altered sensorium & $23(56.09)$ & $16(48.4)$ \\
\hline Vertigo & $17(41.46)$ & $5(15.1)$ \\
\hline
\end{tabular}

Chi square value $=2.57, \mathrm{df} 4, \mathrm{p}$ value $=0.63$

HTCZ $=$ Hydrochlorthiazide, $\mathrm{CTD}=$ Chlorthalidone

The difference in the mean plasma sodium level between the two groups was $5.23 \pm 2.44$ (95\% CI 2.78-7.67) with a lower plasma sodium level in the HTCZ group. The mean plasma sodium level in the HTCZ group was $118 \pm 6 \mathrm{mmol} / \mathrm{L}, \mathrm{SEM}=0.99$ and $124 \pm 3 \mathrm{mmol} / \mathrm{L}, \mathrm{SEM}=0.6$ in the HTCZ and CTD group respectively (Table 3). Angiotensin receptor blockers followed by the ACE 
inhibitors were the common concurrent medication used in either group (Table 4).

Table 3: Mean plasma sodium level with use of hydrochlorthiazide and chlorthalidone.

\begin{tabular}{|llll|}
\hline & $\begin{array}{l}\text { HTCZ } \\
\mathbf{n}=\mathbf{4 1}\end{array}$ & $\begin{array}{l}\text { CTD } \\
\mathbf{n = 3 3}\end{array}$ & $\begin{array}{l}\text { Independent } \\
\text { samples }^{6}{ }^{\prime} \text { ' } \\
\text { test } \mathbf{p} \text { value }\end{array}$ \\
\hline $\begin{array}{l}\text { Plasma } \\
\text { sodium } \\
\text { level }\end{array}$ & $\begin{array}{l}118 \pm 6 \\
\text { SEM }=0.99\end{array}$ & $\begin{array}{l}124 \pm 3 \\
\text { SEM }=0.6\end{array}$ & $<0.0001$ \\
\hline
\end{tabular}

HTCZ = Hydrochlorthiazide, CTD = Chlorthalidone

Table 4: Concurrent medications along with use of hydrochlorthiazide and chlorthalidone.

\begin{tabular}{|lll|}
\hline Medication & $\begin{array}{l}\text { HTCZ } \\
\mathbf{n = 4 1}(\%)\end{array}$ & $\begin{array}{l}\text { CTD } \\
\mathbf{n = 3 3}(\%)\end{array}$ \\
\hline ACEI & $9(21.95)$ & $6(18.18)$ \\
\hline ARB & $16(39.02)$ & $10(30.30)$ \\
\hline PPI & $2(4.87)$ & $5(15.15)$ \\
\hline Thyroid preparations & $1(2.43)$ & $0(0)$ \\
\hline NSAIDS & $4(9.75)$ & $7(21.21)$ \\
\hline AMA (Azithromycin) & $1(2.43)$ & $0(0)$ \\
\hline Valproic acid & $1(2.43)$ & $0(0)$ \\
\hline Anti-parkisonian drugs & $1(2.43)$ & $3(9.09)$ \\
\hline Opioid analgesics & $1(2.43)$ & $0(0)$ \\
\hline Anxiolytics & $4(9.75)$ & $2(6.06)$ \\
\hline Tricyclic antidepressants & $1(2.43)$ & $0(0)$ \\
\hline
\end{tabular}

ACEI - Angiotensin converting enzyme inhibitor, ARB Angiotensin receptor blocker,

PPI - Proton pump inhibitor, AMA - Antimicrobial agents, NSAIDS - Non-stroidal anti-inflammatory agents.

HTCZ $=$ Hydrochlorthiazide, $\mathrm{CTD}=$ Chlorthalidone

\section{DISCUSSION}

Thiazide diuretics (mainly HCTZ and CTD) are often considered as the first choice medications in hypertensive patients. In the present study, hyponatremia (plasma sodium concentration $<135 \mathrm{mmol} / \mathrm{L}$ ) was observed in $13.3 \%$ of the diuretic treated patients, across all ages. The incidence of hyponatremia was about $2.5 \%$ less with the use of CTD. In the Systolic Hypertension in Elderly Program Study (SHEP study), $4.1 \%$ of the diuretic treated patients had hyponatremia and $3.9 \%$ had hypokalemia during the study. ${ }^{13}$ Sunderam et al, have found among elderly patients taking diuretics that $17 \%$ developed hyponatremia compared with only $6.6 \%$ who developed diuretic induced hypokalemia. ${ }^{14}$ The variability in the prevalence and pattern of hyponatremia in diuretic use, reported in the studies, may be due to the different study settings and patient related factors like weight, renal function etc. The present study observed that, unlike the patients on CTD who had mild hyponatremia, patients on HTCZ were prone to moderate and severe hyponatremia. It was also observed that CTD was about $20 \%$ protective for hyponatremia than HTCZ. In a study done by Gantait
$\mathrm{K}$ et al, it was concluded that, across all ages, HCTZ has a ten-fold higher risk than CTD to develop hyponatremia. ${ }^{15}$ The lower occurrence of hyponatremia observed in these studies, may be due to the low dose of CTD used. Other published literature has also concluded that, across all ages, patients on HCTZ have a higher risk of developing hyponatremia. ${ }^{16}$ It has been concluded in some studies that, the risk of hyponatremia in users of CTD is higher than in users of HCTZ when used at the same, but not equipotent dose of 12.5 or $25 \mathrm{mg} /$ day. At the same time, it has been observed by van Blijderveen et al that there was no increased risk of hyponatremia with CTD compared with twice the dose of HCTZ per day, which was needed to achieve similar reduction in blood pressure. ${ }^{10}$ Metaanalyses have suggested that CTD is superior to HCTZ in preventing cardiovascular events, which could not be attributed entirely to the lesser effect of HCTZ on office systolic blood pressure. ${ }^{17}$

All thiazide-type diuretics, including HCTZ, chlorothiazide, and bendroflumethiazide, share the common structure of benzothiadiazine dioxide scaffold. ${ }^{18}$ Thiazide-like diuretics, chlorthalidone, metolazone, and indapamide, lack the characteristic benzene ring but still possess ability to inhibit sodium chloride co-transporter in the distal convoluted tubule. ${ }^{19}$ In vitro studies have indicated the highest binding affinity to distal convoluted tubule of bendroflumethiazide followed by indapamide and CTD, with the lowest value in HCTZ ${ }^{18}$ Both thiazidelike and thiazide-type diuretics exhibit ability to inhibit carbonic anhydrase enzymatic activity. ${ }^{19}$ However, CTD is preferentially taken up by the red blood cells to inhibit carbonic anhydrase enzyme, which may explain exceedingly long half-life of chlorthalidone of 30-72 hours. ${ }^{20}$ In contrast, half-life of HCTZ and other thiazide diuretics are only in the range between 5-15 hours. ${ }^{21}$ From a physiological perspective, two properties of CTD might increase the risk of hyponatremia relative to HCTZ. First, in contrast to HCTZ, CTD activates the sympathetic nervous system, independently of blood pressure, which increases arginine vasopressin plasma levels. Second, CTD's half-life (35-67 hours) is longer than that of HCTZ (7-11 hours), which might put subjects at increased risk when a medical condition disturbs sodium and water balance. ${ }^{10}$ At the equivalent dose, CTD was shown to cause greater reduction in serum sodium than HCTZ, suggesting higher potency in inducing this side effect. However, the risk of hyponatremia of CTD at the daily dose of $25 \mathrm{mg}$ is similar to the risk associated with HCTZ at the daily dose of $50 \mathrm{mg} .^{22}$

In the present study, many of the clinically significant findings were observed to be statistically not significant; this may also be due to a smaller sample size used in this study. Apart from using a small sample size, another limitation of this study was that, since this was a cross sectional study, in the absence of follow up, the antihypertensive efficacy of the diuretics could not be compared along with their potential of causing hyponatremia. Several drugs increase the likelihood of 
developing thiazide induced hyponatremia. Non-steroidal anti-inflammatory drugs, through prostaglandin inhibition, decrease free water clearance. Drugs such as chlorpropamide or selective serotonin reuptake inhibitors are associated with the syndrome of inappropriate antidiuretic hormone secretion, which predisposes to thiazide induced hyponatremia. Polydipsia caused by psychotropic medications also is a predisposing factor.$^{23}$ However, this study did not adjust for the confounding effect of concomitant medications and other reported risk factors like weight, renal function etc. ${ }^{24,25}$

\section{CONCLUSION}

At a lower dose of $6.25-12.5 \mathrm{mg} /$ day, chlorthalidone, when used for the treatment of hypertension, carries a lesser risk of hyponatremia than hydrochlorothiazide. The findings of this study along with the suggestions in various other studies and meta-analysis imply that that, as chlorthalidone is superior to hydrochlorothiazide in preventing cardiovascular events, the benefits of its low dose should be further evaluated relative to hydrochlorothiazide with consideration of the risk of hyponatremia.

Funding: No funding sources

Conflict of interest: None declared

Ethical approval: The study was approved by the Institutional Ethics Committee of M.K.C.G. Medical College, Berhampur, Odisha, India (Approval No. 518/2017)

\section{REFERENCES}

1. The Sixth Report of the Joint National Committee on Prevention, Detection, Evaluation, and Treatment of High Blood Pressure. Arch Intern Med. 1997;157:2413-46.

2. Messerli FH, Grossman E, Goldbourt U. Are betablockers efficacious as first-line therapy for hypertensionin the elderly? A systematic review. JAMA. 1998;279:1903-7.

3. Messerli FH, Makani H, Benjo A, Romero J, Alviar C, Bangalore S. Antihypertensive efficacy of hydrochlorothiazide as evaluated by ambulatory blood pressure monitoring: a meta-analysis of randomized trials. Journal of the American College of Cardiology. 2011;57(5):590-600.

4. Lund BC, Ernst ME. The Comparative Effectiveness of Hydrochlorothiazide and Chlorthalidone in an Observational Cohort of Veterans. The Journal of Clinical Hypertension. 2012;14(9):623-9.

5. Sonnenblick M, Friedlander Y, Rosin AJ. Diureticinduced severehyponatremia. Review and analysis of 129 reported patients. Chest. 1993;103:601-6.

6. Kostis JB, Lacy CR, Hall WD, Wilson AC, Borhani NO, Krieger SD, et al. SHEP Study Group. The effect of chlorthalidone on ventricular ectopic activity in patients with isolated systolic hypertension. The American journal of cardiology. 1994 Sep $1 ; 74(5): 464-7$.
7. Siegel D, Hulley SB, Black DM. Diuretics, serum and intracellular electrolyte levels, and arrhythmias in hypertensive men. JAMA. 1992;267:1083-9.

8. Siscovick DS, Raghunathan TE, Psaty BM. Diuretic therapy for hypertension and the risk of primary cardiac arrest. NEngl J Med. 1994,330:1852-7.

9. Chobanian AV, Bakris GL, Black HR. The Seventh Report of the Joint National Committee on Prevention, Detection, Evaluation, and Treatment of High Blood Pressure: the JNC 7 report. JAMA. 2003;289:2560-72.

10. Van Blijderveen JC, Sabine M. Straus SM, Eline M, Rodenburg EM, Zietse R, et al. Hyponatremia: Chlorthalidone versus Hydrochlorothiazide The American Journal of Medicine. 2014;127:763-71.

11. Byatt CM, Millard PH, Levin GE. Diuretics and electrolyte disturbances in 1000 consecutive geriatric admissions. J R Soc Med. 1990;83:704-8.

12. Mount DB. Fluid and electrolyte disturbances. In: Dennis L. Kasper, editor. Harrison's principles of internal medicine, 19th Edition. New York: McGrewHill Education; 2015:298.

13. SHEP Cooperative Research Group Prevention of stroke by antihypertensive drug treatment in older persons with isolated systolic hypertension. Final results of the Systolic Hypertension in the Elderly Program (SHEP). JAMA. 1991;265:3255-64.

14. Sunderam SG, Mankikar GD. Hyponatraemia in the elderly.Age Ageing. 1983;12:77-80.

15. Gantait K, Ghosh TP, Gantait I, Patra S, Bhunia P. Journal of Medical Science and Clinical Research. 2017;5(1):15286-92.

16. Hwang KS, Kim Gheun-Ho. Thiazide-Induced Hyponatremia. Electrolyte Blood Press. 2010;8:51-7.

17. Roush GC, Holford TR, Guddati AK. Chlorthalidone compared with hydrochlorothiazide in reducing cardiovascular events: systematic review and network meta-analyses. Hypertension. 2012;59:1110-17.

18. Kurtz TW. Chlorthalidone: Don't call it thiazide-like anymore. Hypertension. 2010 Sep;56(3):335-7.

19. Beaumont K, Vaughn DA, Fanestil DD. Thiazide diuretic drug receptors in rat kidney: identification with $3 \mathrm{H}$-metolazone. Proceedings of the National Academy of Sciences of the United States of America. 1988;85(7):2311-4.

20. Dieterle W, Wagner J, Faigle JW. Binding of Chlorthalidone (Hygrotonr) to Blood Components in Man. Eur J Clin Pharmacol. 1976;10(1):37-42.

21. Schiavi P, Jochemsen R, Guez D. Pharmacokinetics of sustained and immediate release formulations of indapamide after single and repeated oral administration in healthy volunteers. Fundamental and clinical pharmacology. 2000;14(2):139-46.

22. Matthews KA, Brenner MJ, Brenner AC. Evaluation of the efficacy and safety of a hydrochlorothiazide to chlorthalidone medication change in veterans with hypertension. Clinical therapeutics. 2013;35(9):142330.

23. Mann SJ. The Silent Epidemic of Thiazide-Induced Hyponatremia. The Journal of Clinical Hypertension. 2008;10(6):477-84. 
24. Chow KM, Szeto CC, Wong TY, Leung CB, Li PK. Risk factors for thiazide-induced hyponatraemia. QJM. 2003;96:911-7.

25. Rodenburg EM, Hoorn EJ, Ruiter R, Lous JJ, Hofman A, Uitterlinden AG, et al. Thiazide-associated hyponatremia: a population-based study. American Journal of Kidney Diseases. 2013 Jul 1;62(1):67-72.
Cite this article as: Mishra SK, Panda A. A comparative analysis of hydrochlorothiazide and chlorthalidone induced hyponatremia at the dose commonly prescribed in clinical practice. Int J Basic Clin Pharmacol 2018;7:935-40. 